\title{
Evaluation of Knowledge, Attitudes and Experience of off-label Drug Prescribing Practice among Physicians in Baghdad City Hospitals
} Aysha M. Shanshal*, and Ahmed H. Ataimish ${ }^{* *}$

* Faculty of Pharmacy, Al-Rafidain University College, Baghdad, Iraq

** Department of Pharmacology and Toxicology, College of Pharmacy, University of Baghdad, Baghdad, Iraq

\section{Abstract}

The objective of this study was to assess the knowledge, attitude, and experience of off-label prescribing practice among physicians working in public hospitals in Baghdad city. This cross-sectional study was performed from November $1^{\text {st }} 2018$ to March 2019 in 17 public hospitals in Baghdad, Iraq. The targeted hospitals were randomly selected at different regions in Baghdad City. A self-administered questionnaire was utilized to collect data from the physicians. Out of the 400 distributed paper questionnaires to a convenience sample of physicians, 383 of them were returned completed. More than half of the participants $(57.2 \%)$ indicated that they were reasonably familiar with the term "off-label drug", 57.7\% mentioned that the most common medical reason for the prescribing off-label drugs was unavailability of alternatives. About two thirds had concerns regarding offlabel drug safety and efficacy. $62.7 \%$ agreed that the Ministry of Health authority should provide an incentive to pharmaceutical companies to perform clinical trials in Iraqi patients, $49.1 \%$ believed that clinical trials that recruit volunteers involve ethical issues. Extensive efforts are required to make programs, regulations and guidelines to control the off-label prescribing practice among the Iraqi healthcare providers at different healthcare settings. Keywords: Attitude, Prescribing practice, off-label prescribing.

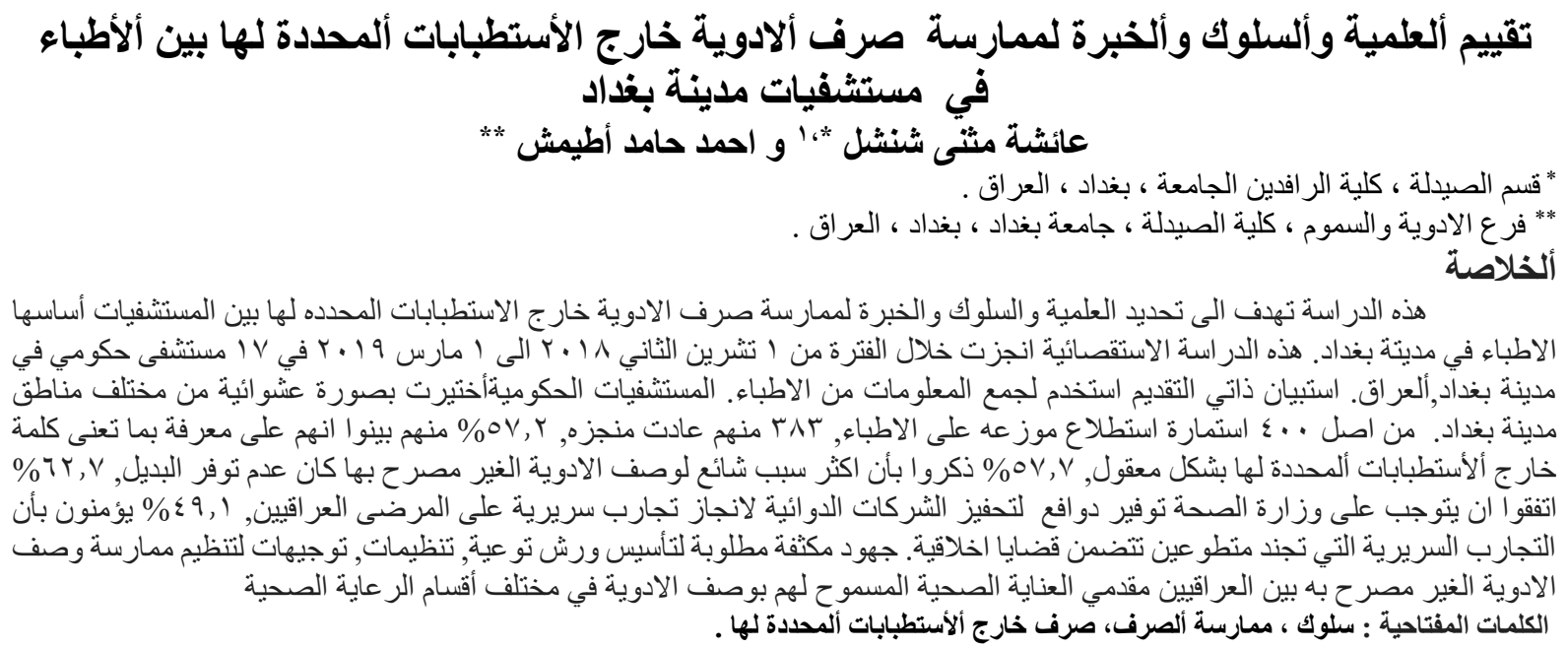

\section{Introduction}

The term off-label drug use (OLDU) is widely used in the medical literature and the media (1). Off-label drug prescribing has not undergone the type of advantage-disadvantage assessment required in the process of medicines' marketing authorization. However, it has been noted that healthcare professionals commonly prescribe medicines off- label with levels of evidence considered to be low. This is principally problematic because off-label use with inadequate strong scientific evidence may be associated with higher rates of adverse events that may harm the patient ${ }^{(2-}$ 4). Off-label prescribing is not certainly bad. It can be beneficial, particularly when the patients have no other approved options like in cancer chemotherapy. Off-label prescribing of a drug or combination of drugs usually represents the standard of care in such cases ${ }^{(5)}$. Off-label prescribing can represent different forms including prescribing drug outside the age range or weight for which the product is licensed (6), for indications not approved in the Product Information Leaflet (PIL) ${ }^{(7)}$, utilizing alternative routes of administration other than that indicated for that formulation in the PIL ${ }^{(8)}$, the use of doses or dose frequencies other than those stated in the PIL ${ }^{(9,10)}$, and using different formulation other than approved one ${ }^{(11,12)}$. As lately reported on the off-label use of medications in the European Union (EU), the prevalence of off-label use in the pediatric and adult population is high in a wide range of therapeutic regions, particularly oncology, psychiatry, neurology and rheumatology ${ }^{(13)}$.

${ }^{1}$ Corresponding author E-mail: rafeef_sh@yahoo.com

Received: 21/ 4 / 2019

Accepted: 18/8 / 2019

Iraqi Journal of Pharmaceutical Sciences 
Many controversies existed and the healthcare professionals generally agree that more work and efforts are needed to prescribe suitable off-label drugs for patients with rare diseases. ${ }^{(14)}$ However, they also concur that potential improper promotion, as well as possibly hazardous prescribing use for these drugs should be obviated ${ }^{(14)}$. The present study was designed to assess the knowledge, attitude, and experience of off-label prescribing practice among physicians in Baghdad city hospitals and clarify the acceptability of this practice among prescribers at different medical specialties in addition to the reasons behind accepting or rejecting this approach.

\section{Methods}

A quantitative cross-sectional study design was used. A self-administered questionnaire was utilized to collect data from the physicians at different healthcare branches in Baghdad City, Iraq. A 25 item questionnaire comprised questions with a combination of tick box responses, 5-6-point scale questions and four open-ended questions were sent to 17 public hospitals. The survey focused on physician knowledge of and reasons for off-label prescribing, concerns about off-label medicines, communications between patients and physicians, and attitudes towards the need for performance of clinical studies. The recruitment process was carried out from November 1, 2018 to March 1, 2019. No incentive was offered to the participants.

\section{Questionnaire development}

In the present study, an English questionnaire especially was developed to evaluate the off-label prescribing practice among Iraqi clinicians. The questionnaire contents were formulated based on questionnaire previously used elsewhere to explore the views, attitudes, knowledge, and perceptions of the prescribers towards the off-label prescribing of medicines ${ }^{(15)}$ Most questions had pre-formulated answers, except few with partially open-ended answers. The questionnaire consisted of 25 questions. The questionnaire was divided into four sections addressing different topics of interest including the participant demographic information, physician familiarity of off-label prescribing practice and its consequences, the reasons behind off-label prescribing, patient involvement in the prescribing process and physician sources of information about off-label drugs. Finally, the questionnaire focused on the clinical trials and the issues associated with dosage determination of off-label medicines to young patients.

\section{Validation of the study tool}

The study questionnaire was pilot tested on a convenience sample of 40 randomly selected physicians to predict the validity and reproducibility of the designed questionnaire. Using the Cronbach alpha, reliability tests yielded good internal consistency for the overall questionnaire items $(\alpha=$ 0.782 ). Test-retest reliability was evaluated by Pearson correlations between time 1 and 2 scores (23 weeks later) on the two completed questionnaires. Test-retest reliability for the overall score was acceptable $(\mathrm{r}=0.83)$. All the participants declared that the questionnaire was clearly understood.

\section{Physicians}

Physicians were recruited from 17 different hospitals that cover the healthcare services at different regions of Baghdad. Four-hundred physicians participated in this cross-sectional study (74 consultants, 72 general practitioners and 254 permanent registrars) who practiced in different disciplines of medicine (32 Internists, 115 Surgeons, 7 Nephrologists, 8 Intensive Care unit, 76 pediatric,50 General and 95 represented other miscellaneous fields).

\section{Inclusion criteria}

The inclusion criteria of the current study included physicians from different specialties at different hospitals in Baghdad with minimum practicing experience of 3 years who provided verbal consent to participate in the study.

\section{Exclusion criteria}

The exclusion criteria of the current study included the rotators and junior physicians with prescribing practice experience of less than 3 years.

\section{Statistical analysis}

Statistical analyses were performed using the IBM Statistical Package for Social Sciences SPSS (version 24.0) and GraphPad Prism version 5.1 software with significance levels set at $P<0.05$. Categorical variables were expressed as numbers and percentages, while continuous variable were expressed as mean \pm SD. Non-parametric tests were utilized to compare knowledge scores, perspectives, and off-label prescribing practices across the different selected clinician demographics (MannWhitney U test for 2 groups and Kruskal-Wallis for more than 2 groups). Validity and reproducibility of the questionnaire were measured by Cronbach's alpha. Chi square test and Exact Fisher's test were used to compare the differences in the perceptions of clinicians who have practiced off-label drug prescribing and those who have the idea and knowledge but do not practice off-label drug prescribing.

\section{Results}

Demographics

Out of the 400 distributed questionnaires to the physicians, $383(95.8 \%)$ of them were returned completed, while 17 (4.2\%) were uncompleted and excluded during analysis. A total of $18.3 \%$ of the participants were consultants, $17.5 \%$ general practitioner, $39.9 \%$ of them were permanent registrar and $24.3 \%$ of them were specialists. 
Regarding the practice field, $8.4 \%$ of them were internist, $30 \%$ surgeons, $1.8 \%$ nephrologists, $2.1 \%$ intensive care, $13.1 \%$ general, $19.8 \%$ pediatricians and $24.8 \%$ represent other miscellaneous specialties. Regarding the duration of practice, $29.25 \%$ of respondents practiced as physicians for $1-4$ years, $27.9 \%$ for 5-10 years and $42.8 \%$ for more than 10 years in service.

\section{Knowledge and views about off-label medicines}

The majority of respondents $(219 ; 57.2 \%)$ indicated that they were reasonably familiar with the term "off-label drug" and found to be significantly greater $(P<0.05)$ than those who are either unfamiliar or highly familiar, $62(16.2 \%)$ mentioned that they were highly familiar with the term "offlabel" drug and $102(26.6 \%)$ were found unfamiliar with this term (Figure 1).

The present study indicated that the forms of the off-label prescribing include prescribing a drug for younger age $(56.9 \%)$, lower than recommended dose $(66.6 \%)$, higher than recommended dose $(57.2 \%)$, choosing an alternative different formulation $(60.3 \%)$, prescribing a drug of different indication $(64.8 \%)$ or utilizing different route of administration (59.8\%) (Table 1).

Table 1. Forms of off label-drugs

\begin{tabular}{||l|c|c||}
\hline Most important forms for off-label prescribing & Frequency $n(\%)$ & Score from 6 (mean \pm SD) \\
\hline Lower than recommended dose & $255(66.6)$ & $2.15 \pm 2.03^{\mathrm{a}}$ \\
\hline Higher than recommended dose & $219(57.2)$ & $1.65 \pm 1.71^{\mathrm{a}}$ \\
\hline At a younger age than recommended & $218(56.9)$ & $1.86 \pm 1.90^{\mathrm{a}}$ \\
\hline Via a different route of administration & $229(59.8)$ & $2.20 \pm 2.06^{\mathrm{a}}$ \\
\hline Different formulation & $231(60.3)$ & $2.26 \pm 2.06^{\mathrm{a}}$ \\
\hline Different indication & $249(64.8)$ & $2.56 \pm 2.11^{\mathrm{a}}$ \\
\hline
\end{tabular}

Values are expressed as frequencies, percentage and mean \pm SD; mean score values with non-identical superscripts $(\mathrm{a}, \mathrm{b})$ among groups are significantly different (Kurksal-Wallis test with Dunn's post hoc test).

In addition, the majority of respondents reported patients (> 40 years of age) and patients $(1$ day -15 years) to be the most likely seen by the targeted physicians $(41.5 \%$ and $37.6 \%$; respectively). On the other hand, patients (16-2. years), patients (21-30years) and (31-40 years) were characterized by the respondents to be less likely seen by the targeted physicians $(32.1 \%, 32.9 \%$ and $36.8 \%$; respectively) (Table 2 ).

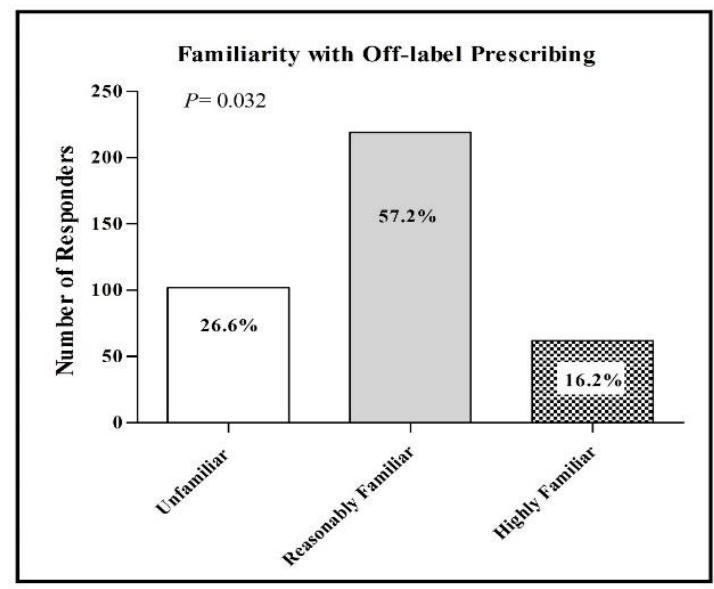

Figure 1. Rating of the targeted physicians according to their familiarity with the off-label prescribing practice. $n=383$ total number; (chisquare test).

The present study indicated that the forms of the off-label prescribing include prescribing a drug for younger age $(56.9 \%)$, lower than recommended dose $(66.6 \%)$, higher than recommended dose $(57.2 \%)$, choosing an alternative different formulation $(60.3 \%)$, prescribing a drug of different indication $(64.8 \%)$ or utilizing different route of administration (59.8\%) (Table 1).
Table 2. The age ranges of patients mostly seen by the targeted physicians ( $n=383$ physicians)

\begin{tabular}{||l|c|c||}
\hline \hline $\begin{array}{l}\text { Age range of } \\
\text { patients (Years) }\end{array}$ & $\begin{array}{c}\text { Frequency } \\
n(\%)\end{array}$ & $\begin{array}{c}\text { Score from 5 } \\
(\text { mean } \pm \text { SD) }\end{array}$ \\
\hline $1-15$ years & $144(37.6)$ & $2.19 \pm 2.0^{\mathrm{a}}$ \\
\hline $16-20$ years & $123(32.1)$ & $1.84 \pm 1.7^{\mathrm{a}}$ \\
\hline 21-30 years & $126(32.9)$ & $1.85 \pm 1.8^{\mathrm{a}}$ \\
\hline 31-40 years & $141(36.8)$ & $1.86 \pm 1.87^{\mathrm{a}}$ \\
\hline Over 40 years & $159(41.5)$ & $2.32 \pm 2.18^{\mathrm{a}}$ \\
\hline
\end{tabular}

Values are expressed as frequencies, percentage and mean $\pm \mathrm{SD}$; mean score values with non-identical superscripts (a, b) among groups are significantly different (Kurksal-Wallis test with Dunn's post hoc test). 
According to the physician's answers, the most common medical reasons for prescribing offlabel drugs were $57.7 \%$ unavailability of alternatives, $17.5 \%$ personal experience, $12 \%$ case reports and $12.8 \%$ mentioned that they don't know (all of the last group don't prescribe off-label drug for their patients) (Figure 2).

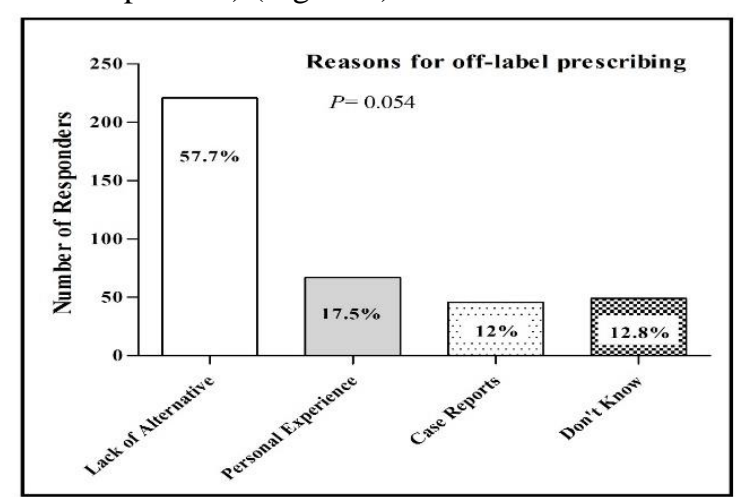

Figure 2.The reasons behind off-label prescribing practice. $n=383$ total number; values of last three options are significantly different (chi-square test).

Views about the safety and efficacy of the off-label medicines
The majority of respondents had major and/or minor concerns regarding the safety (67.6\%), while those who concerned about the efficacy of the prescribed off-label medications represent around $65.5 \%$ of the respondents (Table 3). There was no significant difference between the familiarity of offlabel prescribing and concerns about the safety of off-label medicines during prescribing to their patients; $(p=0.449)$ (chi-square test).

About half of the respondents (52.2\%) felt that the use of off-label medicines increased the likelihood of disadvantages to the patient for several reasons. As they mentioned, it may disadvantage the patient and cause serious ADRs. At the same time other mentioned that they do not have close monitoring or follow up to their patients after administering the drug to observe the ADRs. About $34.2 \%$ of respondents have observed ADRs after using off-label drugs to their patients (Table 3).

Declaring their own practice, approximately half of healthcare providers (55.4\%) admitted to having experienced treatment failure; in spite of that $60.1 \%$ of the physicians knowingly prescribe drugs offlabel for their patients (Table 3).

Table 3.Physicians views about the safety and efficacy of the off-label medicines ( $n=383$ physicians)

\begin{tabular}{|l|c|c|c||}
\hline Questions & \multicolumn{2}{|c|}{ Response $n(\%)$} & \multirow{2}{*}{$\begin{array}{c}\text { P- } \\
\text { value }\end{array}$} \\
\cline { 2 - 3 } & Yes & No & $\mathbf{0 . 0 3}$ \\
\hline Do you knowingly prescribe drugs off-label? & $230(60.1)$ & $153(39.3)$ & \\
\hline Do you realize that off-label prescribing may disadvantage the patients? & $200(52.2)$ & $183(47.8)$ & 0.24 \\
\hline Do you have concerns about the efficacy of the off-label drugs? & $251(65.5)$ & $132(34.5)$ & $\mathbf{0 . 0 2 1}$ \\
\hline Do you have concerns about the safety of the off-label drugs? & $259(67.6)$ & $124(32.4)$ & $\mathbf{0 . 0 2}$ \\
\hline $\begin{array}{l}\text { Have any of your patients experienced ADR after using off-label drugs? } \\
\text { Have any of your patients experienced treatment failure due to the off- } \\
\text { label drug use? }\end{array}$ & $2131(34.2)$ & $252(65.8)$ & $\mathbf{0 . 0 2}$ \\
\hline
\end{tabular}

Values are expressed as frequency and percentage; $n$ : number of the responders; $P$-value indicates significant differences according to Fisher's exact test.

In the present study, only $35.8 \%$ of respondents declared that they request verbal consent from the patient or the patient's parents, $38.6 \%$ of them ask for the consent of their supervisor and only $40.7 \%$ of the interviewed physicians routinely inform their patients that they dispensed an off-label drug for them and inform them about its use and the expected outcome (Table 4). There was a significant relationship between the familiarity of off-label drug prescribing and asking for consent from the patient and informing the patient about the off-label dug $(p=0.008,0.01)$ respectively. While the result showed that there was no significant relationship between the familiarity and asking consent from the supervisor, $(p=0.7)$ (chi-square test). 
Table 4. concerns of the physicians about ask for consent for prescribe off-label drug ( $n=383$ physicians)

\begin{tabular}{|l|c|c|c||}
\hline \hline Questions & \multicolumn{2}{|c|}{ Response $n(\%)$} & P- \\
value
\end{tabular}

Values are expressed as frequency and percentage; $n$ : number of the responders; $P$-value indicates significant differences according to Fisher's exact test.

\section{Information sources}

When the healthcare providers were asked how they became familiar with the terminology of off-label drugs, $21.1 \%$ of the respondents mentioned that they had gained their knowledge from the BNF, $17.2 \%$ from a colleagues ' experience, $54.8 \%$ from all the mentioned before and $6.8 \%$ from other nonrecognized sources (Figure 3 ).

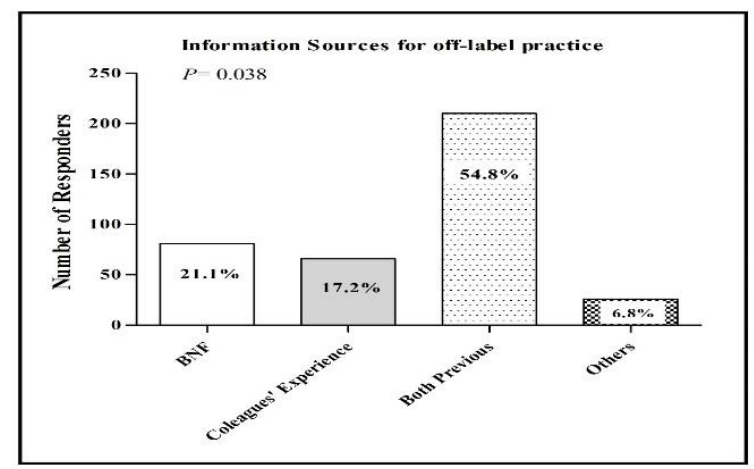

Figure 3. The information sources for the offlabel prescribing practice. $n=383$ total number; values of $\mathrm{BNF}$, colleague experience and others are significantly different (chi-square's test)

\section{Clinical trials on volunteers}

In this section, when the healthcare providers were asked about the need for more clinical trials to address the issue of off-label drugs use, $71 \%$ of them mentioned that it is important to provide more drug formulations, $44.4 \%$ of the respondents believed that all current drugs that have not been evaluated in younger ages should trialed in those populations and $67.6 \%$ thought that all new drugs should be trialed in different age groups prior to use. Moreover, approximately more than half of the respondents $(62.7 \%)$ agreed that the Ministry of Health $(\mathrm{MOH})$ authority should provide an incentive to stimulate pharmaceutical companies to perform clinical trials in Iraqi patients (Table 5).

There is limited information about their efficacy in younger age patients which consider riskiest group. Younger patients have different physiology, Basal Metabolic Rate, metabolism, surface area and different body weight. About $49 \%$ of the respondents do not believe that all current drugs that have not been evaluated in younger ages should be trialed in those populations. Some of the respondents disagreed with trying new drugs indifferent age groups prior to use for ethical considerations and nature of our society.

Table 5. Views of the physicians about the need for more drug formulations and trialing all new drugs in different age groups prior to use ( $n=383$ physicians)

\begin{tabular}{|c|c|c|c|}
\hline \multirow[t]{2}{*}{ Questions } & \multicolumn{3}{|c|}{ Response $n(\%)$} \\
\hline & Yes & No & Do not know \\
\hline Is it important to develop more drug formulations? & $272(71)$ & $42(11)$ & $69(18)$ \\
\hline Should all new drugs be trialed in different age groups prior to use? & $259(67.6)$ & $49(12.8)$ & $75(19.6)$ \\
\hline $\begin{array}{l}\text { Should the MOH authority provide incentives to stimulate } \\
\text { pharmaceutical companies to perform clinical trials on Iraqi } \\
\text { patients? }\end{array}$ & $240(62.7)$ & $59(15.4)$ & $84(21.9)$ \\
\hline $\begin{array}{l}\text { Should all current drugs that have not been evaluated in younger } \\
\text { ages trialed in those populations? }\end{array}$ & $170(44.4)$ & $78(20.4)$ & $135(35.2)$ \\
\hline
\end{tabular}

Values are expressed as frequency and percentage; $n$ : number of the responders.

However, only $43.4 \%$ of the respondents indicated that they have the willingness to be actively involved in a clinical trial, and about $44.6 \%$ of them accepted the idea of recruiting their own patients for a clinical research. There was no significant relationship between willingness to be involved in clinical trial and the specialty of the physicians. The participants were also asked if they accepted to 
enroll their relatives in the clinical trials. Only $37.6 \%$ of the respondents agree to allow their relative to participate in a clinical trial. About half of physicians (49.1) believed that clinical trials that recruit volunteers involve ethical issues (Table 6).

Several reasons make the physicians believed that clinical trials that recruit volunteers involve ethical issues including believing that uncertain efficacy of off-label drug may lead to unexpected result that may harm the patient; for social and religious consideration, to avoid personal problem with the patients.

Table 6. Views of the physicians about clinical trials in Iraqi patients ( $n=383$ physicians)

\begin{tabular}{|l|c|c|c||}
\hline Questions & \multicolumn{2}{|c|}{ Response $n(\%)$} \\
\cline { 2 - 4 } & Yes & $\begin{array}{c}\text { No } \\
\text { opinion }\end{array}$ \\
\hline Would you like to be actively involved in conducting clinical trials? & $166(43.4)$ & $138(36)$ & $79(12.6)$ \\
\hline Would you like to recruit your patients for a clinical trial? & $171(44.6)$ & $107(27.9)$ & $105(27.5)$ \\
\hline Would you allow your own relatives to participate in a clinical trial? & $144(37.6)$ & $155(40.5)$ & $84(21.9)$ \\
\hline $\begin{array}{l}\text { Do you believe that clinical trials that recruit volunteers involve } \\
\text { ethical issues? }\end{array}$ & $188(49.1)$ & $112(29.2)$ & $83(21.7)$ \\
\hline \hline
\end{tabular}

Values are expressed as frequency and percentage; $n$ : number of the responders.

\section{Discussion}

The data of the present study showed that the majority of respondents mentioned that they were either familiar or reasonably familiar with the term "off-label drug". The most common form of prescribing off-label drug was prescribing lower than the recommended dose. The results were approximately equivalent to the results of prevalence of off-label use in Jordan and North Ireland ${ }^{(16,17)}$. However, it is possible that a decrease in the dose could significantly increase risk of treatment failure. The other causes related to the increases in dose, frequency, or duration of administration, compared with the approved dosing regimens, can actually increase the risk of toxicity of a marketed drug ${ }^{(18-20)}$.

Prescribing modified formula (dosage form) of the drug for patients who have difficulty in swallowing like in Parkinson patients or patient with mandibular fracture is considered as a common solution to ease the administration of the drug; e.g., crushing the tablets or open the capsules. However, the clinical consequences of such practice can be inappropriate and may harm the patient. Such alteration of formula may affect the drug's absorption and can result sometimes in fatal overdose, or oppositely under dosing, rendering the treatment inefficient (21-24). Similarly, the change in the route of drug administration may create series of new problems. The modified routes of administration may create problems concerned with increased local concentrations, sterility, pyrogenicity, hypersensitivity (e.g., airway reactivity), difference in pharmacokinetic and pharmacodynamics, which can seriously increase the risks of toxicity or adverse effects ${ }^{(25)}$.

In the present study, the respondents reported patients ( $>40$ years) $(41.56 \%)$ and patients (1-15 years) $(37.6 \%)$ to be the most likely seen by the targeted physicians. In other study show that geriatric and pediatric patients remain poorly participate in clinical trials that evaluate the premarketing efficacy and safety of novel therapies. It is perhaps not unpredictable that off-label prescribing is particularly common in these groups (26).

The present study showed that around half $(52.5 \%)$ of the respondents felt that prescribing off-label medicines increased the likelihood of disadvantages to the patient. The majority of respondents $(67.6 \%)$ had major and/or minor concerns regarding the safety, while those who had concerned about the efficacy of the prescribed offlabel medications represent about two third of the respondents $(65.5 \%)$. This result was in tune with many previously reported data that focus on the concerns of disadvantaging the patient's health $(27,28)$.

Approximately more than half of healthcare providers $(55.4 \%)$ admitted to having experienced treatment failure, while third of them (34.2\%) experienced ADR after using off-label drugs to their patients. In spite of that, more than half of the physicians $(60.1 \%)$ knowingly prescribe drugs off-label for their patients as a usual practice. This unusual behavior needs to be thoroughly evaluated to uncover the exact reasons behind such attitude. Attentiveness to medicines safety is very important, although there is an evidence that offlabel use is frequently inappropriate and may expose patients to a very high risk of ADRs ${ }^{(4,29)}$. Moreover, this high percent of off-label drug misuse may lead to waste of economic resources ${ }^{(30)}$.

Regarding the prescribers' practices, the present study revealed that only third of the respondents $(35.8 \%)$ mentioned that they request verbal consent from the patient or the patient's relatives; while more than third of them $(38.6 \%)$ ask for the consent of their supervisor and only $40.7 \%$ of the interviewed physicians routinely informed 
their patients that they dispensed an off-label drug for them and informing them about its use and the expected outcome. Nowadays, the prescribers have a corresponding legal and ethical duty to acknowledge all of the facts that are relevant to their patients' treatment decisions. Patients deserve to know any inherent risks of a prescribed medication. Also, asking for informed consent for off-label medication use will protect physicians against legal issue ${ }^{(31)}$.

When the healthcare providers were asked about the reasons behind prescribing off-label drug, more than $50 \%$ of the respondents $(57.7 \%)$ mentioned that they prescribe off-label drug as a result of unavailability of alternatives; while about $17.5 \%$ referred to their personal experience and $12 \%$ case reports. In addition, $12.8 \%$ did not declare the reasons for its use. Approximately all the later $12.8 \%$ of physicians did not prescribe off-label drug during their practice history. Also, $21.1 \%$ of prescribers had gained their knowledge from the BNF, $17.2 \%$ from a colleagues ' experience, $54.8 \%$ responded from all the mentioned before and other $7 \%$ not recognized sources.

Unfortunately, the physician's attitude toward offlabel prescribing has no strong scientific evidence. This could be explained by the absence of awareness of such prescribing approach. Case reports are not considered as well-trusted sources; meanwhile, the frequent use of personal experience, previous patient prescription notes and colleague experience, all of which may lead to inaccurate off-label prescribing. BNF can be useful, but offer obvious guidance only after high-quality research has evaluated a specific off-label use ${ }^{(32)}$. According to the FDA, approved drugs that are allowed for an unapproved use are misbranded ${ }^{(33)}$.

In the present study, the healthcare providers addressed the need for more clinical trials to clarify the issue of off-label drugs use; nearly $71 \%$ of them mentioned that it is important to provide more drug formulations, two thirds of the respondents $(67.6 \%)$ believed that all the current drugs that have not been evaluated in younger ages should be trialed in those populations to make sure they are safe. Approximately two thirds of the respondents $(62.7 \%)$ agreed that the $\mathrm{MOH}$ authority should provide an incentive to stimulate pharmaceutical companies to perform clinical trials in Iraqi patients. Clinical trials introduce 'a way to pool controlled observations in an objective and scientific way, helping clinicians to decide what is the best therapy for the patient' ${ }^{(34)}$.

In spite of that about $20.4 \%$ of the physicians make objections to conducting clinical trials in Iraq for several reasons including either for social, religious and economic considerations, or low education. However, in considering the idea of taking part in clinical trials, only $43.3 \%$ of respondents indicated that they have the willingness to be actively involved in a clinical trial and about $44.6 \%$ of them accept the idea of recruiting their own patients for a clinical research. There was no relationship between willingness to be involved in clinical trial and the specialty of the physicians.

The participants were also asked if they accepted to enroll their relatives in the clinical trials; only $37.6 \%$ of the respondents agreed to enroll their relative to participate in a clinical trial and approximately half of physicians believed that clinical trials that recruit volunteers involve ethical issues.

Strategies to encourage physician participation in clinical trials include financial and nonfinancial stimulus, sufficient training, research questions that are in agreement with physician interests and have clear potential to improve patient health care ${ }^{(35)}$

The development of new health care management models where patients involve in clinical trials and the expansion of information technology are additional factors that contribute to enhance this change ${ }^{(36)}$. Patient-centered medicine cannot be practiced without patients involving in their own health care decisions and in the research that needs such decisions ${ }^{(37)}$.

Ethics and regulatory review procedures are essential for protection the safety and interests of the participants. However, overly strict ethical and regulatory systems could limit research capacity $(38,39)$.

After all, all drug treatment, all cases involving the use of drugs in an off-label use should be thoroughly documented in the medical report of the patient, including the clinical outcomes of such therapy, could extremely improve the knowledge in this area ${ }^{(40)}$.

\section{Study limitations}

There have been other variables difficult to control, that may impact the results and not included in the study, including availability of alternatives for the prescribed medications, clinical picture of the patient, influence of relatives, arguments by the prescribers, and importance of treatment. Other potential limitation of the present study could be the absence of clinical outcome follow-up for dispensing off-label medications, which could help in assessing their efficacy.

\section{Conclusion}

The majority of participants were reasonably familiar with the concept of off-label medicines and prescribe off-label drug knowingly. They believed that this practice may disadvantage the patient due to concerns about efficacy and safety that may be associated with increased risks of ADRs. Although the respondents very well recognized the ethical issue of the off-label drugs, most of them do not request consent neither from the patients nor from the health authority seniors. Extensive efforts are required to make programs, 
regulations and guidelines to control the off-label prescribing practice among the Iraqi healthcare providers who are authorized to prescribe medications at different healthcare settings.

\section{Acknowledgments}

The presented data was abstracted from MSc thesis submitted to the Department of Clinical Pharmacy, College of Pharmacy -- University of Baghdad. The authors thank Professor Dr. Saad A. Hussain for the instructions and valuable advice, and specifically for sharing his knowledge concerning off label prescribing with us. They also appreciate the support of all the physicians who participate and help to perform this project.

\section{References}

1. Radley D, Finkelstein S and Stafford R. Offlabel prescribing among office-based physicians. Arch Intern Med. 2006; 166(9):1021-1026.

2. Blanco R, Muñoz G, Cárdenas A, Ocaña-Riola R and Del Prado-Llergo J. Assessment of off-label prescribing: profile, evidence and evolution. Farmacia Hospitalaria. 2017; 41(4):458-469.

3. Danés I, Agustí A, Vallano A, Alerany C, Martínez J, Bosch JA, et al. Outcomes of offlabel drug uses in hospitals: a multicentric prospective study. Eur J Clin Pharmacol. 2014; 70(11):1385-93.

4. Eguale T, Buckeridge D, Verma A, Winslade N, Benedetti A, Tamblyn R, et al. Association of off-label drug use and adverse drug events in an adult population. JAMA Intern Med. 2016; 176 (1): 55-63

5. Di Francesco L, Lopez Contreras L, Sacco A and Patrignani P. New insights into the mechanism of action of aspirin in the prevention of colorectal neoplasia. Curr Pharm Des. 2015; 21(35):51165126.

6. Shah $\mathrm{S}$, Hall M, Goodman D. Off-label drug use in hospitalized children Arch Pediatr Adolesc Med. 2007; 161(3):282-290.

7. Briem $S$ and Lorenz H. Current off-label use of methotrexate for chronic inflammatory rheumatic disease. Z Rheumatol. 2011; 70(2):123-128.

8. Bernards C. Recent insights into the pharmacokinetics of spinal opioids and the relevance to opioid selection. Curr Opin Anaesthesiol. 2004; 17(5):441-447.

9. Daukes S, McLay J, Taylor M, Simpson C and Helms P. Antibiotic prescribing for children. $\mathrm{Br}$ J Clin Pharmacol. 2003; 56(1):92-95.

10. Klein J. Is acute otitis media a treatable disease? N Engl J Med. 2011; 364(2):168-169.

11. Smyth J. Time for nurses to take charge. Nurs Manag (Harrow) 2010; 16(10):11.

12. Gimenes F, Pareira R, Horak A, Oliveira C, Reis A and da Silva P. Medication incidents related to feeding tube: A cross-sectional study. Afr J Pharm Pharmacol. 2017; 11(26):305-313.
13. Lindell-Osuagwu L, Hakkarainen M, Sepponen $\mathrm{K}$, Vainio $\mathrm{K}$, Naaranlahti $\mathrm{T}$ and Kokki $\mathrm{H}$. Prescribing for off-label use and unauthorized medicines in three paediatric wards in Finland, the status before and after the European Union Paediatric Regulation. J Clin Pharm Ther. 2014; 39(2):144-153.

14. Hampton T. Experts weigh in on promotion, prescription of off-label drugs. JAMA. 2007; 297(7):683-684.

15. J S McLay, M Tanaka, S Ekins-Daukes, and P J Helms . A prospective questionnaire assessment of attitudes and experiences of off label prescribing among hospital based paediatricians . Arch Dis Child. 2006 Jul; 91(7): 584-587.

16. Mukattash $T$, Hawwa $A$, Trew $K$, James $C$ and Mcelnay J. Healthcare professional experiences and attitudes on unlicensed/off-label paediatric prescribing and paediatric clinical trials. European Journal of Clinical Pharmacology. 2011; 67 (5):449-461.

17. Mukattash T, Alzoubi K, Abuirjie A, Jarab A, Abu Farha R, Nusair M, et al. Perceptions and attitudes towards off-label dispensing for pediatric patients, a study of hospital based pharmacists in Jordan. Saudi Pharm J. 2018; 26(1):20-24.

18. Ekins-Daukes S, Helms P, Simpson C, Taylor M and McLay J. Off-label prescribing to children in primary care. Retrospective observational study. Eur J Clin Pharmacol. 2004;60:349-53.

19. McIntyre J, Conroy S, Avery A, Corns H and Choonara I. Unlicensed and off-label prescribing of drugs in general practice. Arch Dis Child. 2000;83(6):498-501.

20.Ekins-Daukes S, McLay J, Taylor M, Simpson C and Helms P. Antibiotic prescribing for children. Too much and too little? Retrospective observational study in primary care. Br J Clin Pharmacol. 2003;56:92-5.

21. Morris H. Administering drugs to patients with swallowing difficulties. Nurs Times. 2005; 101(39):28.

22. Strachan I and Greener M. Medication-related swallowing difficulties may be more common than we realise. Pharmacy in Practice. 2005; 15(9):411-414.

23. Wright D and Tomlin S. How to help if a patient can't swallow. Pharmaceutical Journal. 2011; 286:271-274.

24. Wright D, Chapman N, Foundling-Miah M, Ralph Greenwall, Richard Griffith, Anne Guyon , et al. Consensus guideline on the medication management of adults with swallowing difficulties. Produced by Connectmedical, a division of Medendium Group Publishing Ltd. 2006.

25. Dawidczyk C, Kim C, Park J, Russell L, Lee K, Pomper $\mathrm{M}$ and Searson P.State-of-the-art in design rules for drug delivery platforms: Lessons 
learned from FDA-approved nanomedicines. J Control Release. 2014;187:133-44.

26. Hames A, Wynne H. Unlicensed and off-label drug use in elderly people. Age Ageing. 2001; 30(6):530-531.

27. Martin C. Off-label use of medications: innovative prescribing or risky business? Consult Pharm. 2010; 25(12):806-810.

28. Herring C, McManus A and Weeks A. Off-label prescribing during pregnancy in the UK: an analysis of 18,000 prescriptions in Liverpool Women's Hospital. Int $\mathbf{J}$ Pharm Pract. 2010;18(4):226-229.

29. Good C and Gellad W. Off-Label Drug Use and Adverse Drug Events. Turning up the Heat on Off-Label Prescribing. JAMA Internal Medicine. 2016; 176 (1): 63-4.

30.Danés I, Agustí A, Vallano A, Alerany C, Martínez J, Bosch JA, et al. Outcomes of offlabel drug uses in hospitals: a multicentric prospective study. Eur J Clin Pharmacol. 2014;70(11):1385-93.

31. Corny J, Bailey B, Lebel D and Bussieres F., Unlicensed and off-label drug use in paediatrics in a mother-child tertiary care hospital. Paediatr. Child. Health. 2016; 21(2): 83-87.

32. Gazarian M, Kelly M, McPhee R, Graudins V, Ward L, Campbell J. Off-Label Use of Medicines: Consensus Recommendations for Evaluating Appropriateness. Medical Journal of Australia. 2006;185(10):544-548.
33. Blackwell E, Beck M. Drug Manufacturers' First Amendment Right to Advertise and Promote Their Products for Off-Label Use: Avoiding a Pyrrhic Victory. Food and Drug Law Journal. 2003; 58(3):439-62.

34. Lader W, Cannon P, Ohman M, Ohman M, Newby K, Sulmasy P et al. American College of Cardiology Foundation. The clinician as investigator: participating in clinical trials in the practice setting. Circulation. Soc Sci Med 2004;109(21):2672-2679.

35. Rahman S, Majumder A, Shaban F, Rahman N, Ahmed M, Abdulrahman B, D'Souza J. Physician participation in clinical research and trials: issues and approaches. Dovepress j. 2011; 7(2):85-93.

36. Porter ME. What is value in health care? $\mathrm{N}$ Engl J Med. 2010;363:2477-2481.

37. Tinetti E, Basch E. Patients' responsibility to participate in decision making and research. JAMA. 2013;309:2331-2332.

38. Hearn J, Sullivan R. The impact of the 'clinical trials' directive on the cost and conduct of noncommercial cancer trials in the UK. Eur $\mathbf{J}$ Cancer. 2007;43:8-13.

39. Sullivan R. The good, the bad, and the ugly: effect of regulations on cancer research. Lancet Oncol. 2008;2045(07)70388-1.

40. Schubert S, Neininger M, Smers S, Winter A, Frontini R, Bertsche A, et al. Electronic drug prescription - auto pilot for drug therapy? Med Monatsschr Pharm. 2015; 38(6):224-230.

Baghdad Iraqi Journal Pharmaceutical Sciences by bijps is licensed under a Creative Commons Attribution 4.0 International License. Copyrights@ 2015 College of Pharmacy - University of Baghdad. 